\title{
TRABALHO PRECOCE E ACIDENTES OCUPACIONAIS NA ADOLESCÊNCIA
}

\author{
Child labor and occupational accidents in the adolescence \\ Trabajo precoz y accidentes de trabajo en la adolescencia
}

\author{
Márcia Elena Andrade Santos \\ Christiano Gripp Brito ${ }^{3}$
}

\author{
Maria Yvone Chaves Mauro \\ Débora Campos Machado ${ }^{4}$
}

\begin{abstract}
RESUMO
Estudo transversal, descritivo e quantitativo, com o objetivo de investigar a ocorrência de acidentes ocupacionais em adolescentes trabalhadores. Realizado de abril a agosto de 2008, com uma amostra aleatória de 308 adolescentes entre 14 e 18 anos de idade. Os resultados evidenciaram que 168 (54,5\%) eram trabalhadores, 42\%, desses, alegaram ter sofrido acidentes típicos, $(18,5 \%)$ acidentes de trajeto, $14,9 \%$ afastaram-se do trabalho, $51,4 \%$ não tinham carteira assinada e a maioria era do sexo masculino. Os cortes e perfurações foram os acidentes mais ocorridos $(27,5 \%)$, a queimadura constituiu o principal agravo $(26,9 \%)$ e as partes do corpo mais afetadas foram mãos e dedos (40,4\%). Conclui-se que os acidentes ocupacionais configuramse como uma expressão da violência contra os jovens trabalhadores e um grave problema de Saúde Pública. Deve ser incorporado com prioridade na agenda dos serviços públicos e o enfermeiro, junto à equipe de saúde, podem ser os principais articuladores desse processo.
\end{abstract}

Palavras chave: Adolescente. Trabalho de menores. Acidentes de trabalho. Saúde do trabalhador. Enfermagem.

\begin{abstract}
This is a cross-sectional descriptive and quantitative study, which aimed to investigate the occurrence of occupational accidents in adolescent workers. It was conducted from April to August 2008, with a random sample of 308 adolescents between 14 and 18 years of age. The results showed that 168 (54.5\%) were workers, $42 \%$ of those claimed to have suffered typical occupational accidents; $18.5 \%$ were commuting to work when the accident occurred; $14.9 \%$ were prevented from working; $51.4 \%$ did not had a formal work contract and most were male. Cuts and perforations were the most frequent accidents (27.5\%), burning was the main injury (26.9\%) and parts of the body most affected were hands and fingers (40.4\%). This study concluded that occupational accidents are configured as an expression of violence against young workers and a serious public health problem. This topic should be incorporated with priority on the agenda of public health services and the nurse, with the health team, may be the prime movers of this process.
\end{abstract}

Keywords: Adolescent. Child Labor. Occupational Accidents. Occupational Health. Nurse

\section{Resumen}

Estudio transversal, descriptivo y cuantitativo, que tiene como finalidad investigar la ocurrencia de accidentes de trabajo en los trabajadores jóvenes. Realizado entre abril y agosto del 2008, con una muestra aleatoria de 308 adolescentes de 14 y 18 años de edad. Los resultados mostraron que 168 $(54,5 \%)$ eran trabajadores, el $42 \%$ de éstos afirma haber sufrido accidentes típicos, 18,5\% fueron accidentes de trayecto, el $14,9 \%$ no pudieron trabajar después del accidente, el $51,4 \%$ no tenía un contrato formal de trabajo y la mayoría era del sexo masculino. Cortes y pinchazos fueron los accidentes con mayor incidencia $(27,5 \%)$, la quemadura fue la lesión principal $(26,9 \%)$ y las partes del cuerpo más afectadas fueron las manos y los dedos $(40,4 \%)$. Se concluyó que los accidentes de trabajo se caracterizan como una expresión de la violencia contra los trabajadores jóvenes y como un grave problema de salud pública. Por lo tanto, esta cuestión debería ser incorporada con prioridad en la agenda de los servicios públicos de salud y del enfermero (a), al lado del equipo de salud, quienes pueden ser los principales impulsores de este proceso.

Palabras clave: Adolescente. Trabajo de menores. Accidentes de Trabajo. Salud Laboral. Enfermería

'Mestre em Enfermagem pela Faculdade de Enfermagem da UERJ. Especialista em Enfermagem em Saúde Pública pela Escola de Enfermagem da UFMG. Enfermeira do CEREST/Ipatinga. Docente do Centro Universitário do Leste de Minas Gerais - Ipatinga. Brasil. E-mail: marciaelenaenf@yahoo.com.br., ²Doutora em Enfermagem. Professora Visitante Titular do Departamento de Enfermagem de Saúde Pública e do Programa de Pós-graduação-Curso de Mestrado da Faculdade de Enfermagem da UERJ. Enfermeira do Trabalho e Ergonomista. Brasil. E-mail: mycmauro@uol.com.br, ${ }^{3}$ Aluno do $8^{\circ}$ período do Curso de Enfermagem do Centro Universitário do Leste de Minas Gerais - Ipatinga. Brasil. E-mail: grippchris@notmail.com, ${ }^{4}$ Graduanda do Curso de Enfermagem do Centro Universitário do Leste de Minas Gerais Unileste - Ipatinga. Brasil. E-mail: deboracamposmachado@yahoo.com.br 


\section{INTRODUCÃO}

Atualmente, a adolescência é compreendida muito além da sua demarcação temporal, indivíduos entre 12 e 18 anos de idade, conforme o Estatuto da Criança e do Adolescente (ECA), ou entre 10 e 19 anos, como definido pela Organização Mundial de Saúde. ${ }^{1,2}$ Deve-se incorporar a ideia de que essa etapa representa um fenômeno individual e social da vida humana, uma experiência pela qual todo ser humano passa para entrar na vida adulta. ${ }^{3}$

Esta concepção ampliada da adolescência extrapola as transformações físico-corporais próprias dessa fase e abrange os processos produzidos no âmbito das sociedades, no concreto da vida, na construção e reconstrução, na apropriação ou não de seus bens e valores materiais e culturais, na interação destes com os processos somáticos, genéticos e físicoambientais, definindo-se nos diversos modos de viver do adolescente. $^{3}$

Esse é um período extremamente relevante para a construção da identidade individual e social do jovem, devendo, porém, ser considerada a vulnerabilidade e os riscos a que estão expostos os adolescentes em suas formas de inserção na sociedade. ${ }^{3}$

Dentre os espaços de inserção do adolescente, destacamse os locais de trabalho e de preparação profissional, que podem influenciar de forma positiva ou negativa 0 desenvolvimento físico e psicossocial desses indivíduos.

Os aspectos positivos da experiência do trabalho na adolescência ocorrem quando 0 adolescente vivencia um processo de aprendizagem, sendo preparado para desempenhar atividades profissionais e ter capacidade de discernimento para lidar com diferentes situações no âmbito profissional, ampliando suas possibilidades de futuro $\mathrm{e}$ promovendo sua cidadania. ${ }^{4,5}$

0 trabalho precoce torna-se negativo para o jovem quando se estabelece uma competição entre as atividades laborais e as atividades escolares, de esporte e lazer. Nesse caso, o trabalho constitui-se em fonte de desgaste e pode afetar o desenvolvimento emocional, cognitivo e físico do adolescente, por impedi-lo de dedicar-se às atividades extracurriculares, como as lúdicas e sociais próprias da idade. Pode, assim, dificultar sua inserção social, o convívio com seus pares e familiares, impor a renúncia a um grau de escolarização maior, inibir o desenvolvimento de suas potencialidades e expô-lo às doenças e acidentes decorrentes das atividades laborais. ${ }^{4-6}$

0 aproveitamento do trabalho adolescente vem acompanhando o desenvolvimento da história do trabalho através dos tempos. Essa exploração persistiu entre diversos povos pelo mundo, causando repulsa à sociedade, o que impulsionou a criação de leis de proteção ao menor, em uma tentativa de acabar com o proveito do seu trabalho de forma exploratória e precária. ${ }^{7}$
Para alguns autores ${ }^{4}$, só recentemente, no Brasil, é que a temática do trabalho precoce tornou-se objeto de discussão e gerador de posições relevantes que proporcionaram uma maior visibilidade ao trabalho na adolescência e sua abordagem como problema social.

Atualmente, a legislação brasileira permite 0 ingresso precoce de jovens entre 16 e 18 anos ao mercado de trabalho e os protege, garantindo-lhes os direitos trabalhistas e previdenciários. Admite, ainda, o trabalho para os que estão com a idade entre 14 e 16 anos, porém, na condição de aprendizes, inseridos em um programa de formação técnicoprofissional, ministrado segundo as diretrizes e bases da legislação em vigor no País. As atividades laborais realizadas por crianças e adolescentes menores de 14 anos são proibidas pela Emenda Constitucional $n^{0} 20$ de 15/12/1998. ${ }^{6}$

0 ECA vedou 0 trabalho de crianças e adolescentes: 0 noturno (de 22h às 5h); 0 considerado perigoso, insalubre e penoso; realizado em locais prejudiciais à sua formação e ao desenvolvimento físico, psíquico, moral e social; em horários que não permitam a frequência escolar. ${ }^{1}$ Entretanto, parece não haver consciência dos empregadores e da sociedade em geral de que certas ocupações são danosas e causam riscos de acidentes e de adoecimentos aos jovens trabalhadores. Essas situaç̃oes de descumprimento da lei persistem e ainda são reais em várias regiões do Brasil.

llustrando tais considerações, os dados apontados na Pesquisa Nacional por Amostragem Domiciliar (PNAD) em 2006 mostrou que havia, naquele ano, 5,1 milhões de pessoas ocupadas na faixa etária entre 5 e 17 anos, com uma taxa de ocupação de $11,5 \%$, revelando uma dura realidade de crianças e adolescentes em situação de trabalho no Brasil. Dentre as crianças e jovens trabalhadores, $45,9 \%$ estavam inseridas no trabalho doméstico, $36,1 \%$ não recebiam remuneração e, em média, dedicavam 10,4 horas semanais a esses afazeres. Mais da metade nunca recebeu treinamento ou orientação para evitar acidentes ou doenças ocupacionais, sendo que 273 mil sofreram acidentes ou doenças devidas às atividades laborais. Os dados encontrados evidenciaram que $24,8 \%$ dos jovens de 15 a17 anos não iam à escola porque precisavam trabalhar ou ajudar nos afazeres domésticos. ${ }^{8}$

0 trabalho precoce configura-se como um grave problema de Saúde Pública no Brasil e um dos problemas sociais mais relevantes para os indivíduos desta faixa etária, na atualidade. Torna-se, portanto, necessário compreender sua complexidade e os riscos que podem acarretar à saúde dos jovens trabalhadores.

Entre os danos causados pela inserção precoce do adolescente no mercado de trabalho destacam-se os acidentes ocupacionais, considerados por vários estudiosos $05^{5,9}$ uma forma de violência contra o trabalhador, principalmente o jovem, devido ao fato de poderem acarretar-he incapacidades permanentes ou temporárias, e até a morte. Esses agravos representam uma importante causa de morbimortalidade entre os indivíduos 
Trabalho precoce e acidentes ocupacionais Santos MEA, Mauro MYC, Brito CG, Machado DC

desse grupo etário. São de notificação compulsória, de acordo com a Portaria n. 777 de 2004. Esta Portaria tem como objetivo integrar a rede de serviços do SUS voltados à assistência ao trabalhador e à vigilância dos ambientes laborais, evidenciando que os acidentes de trabalho entre jovens merecem atenção especial das políticas públicas do país ${ }^{6,10}$.

Diante da magnitude que esses eventos representam para os jovens trabalhadores, percebeu-se a necessidade de delinear como questão de estudo "Como se caracteriza a ocorrência de acidentes ocupacionais em adolescentes trabalhadores, estudantes da Escola Estadual João XXIII em Ipatinga?" no intuito de subsidiar a elaboração de políticas públicas de prevenção. Dessa forma, definiu-se como objetivo geral: investigar a ocorrência de acidentes ocupacionais em adolescentes trabalhadores, estudantes da Escola Estadual João XXIII em Ipatinga. E como específicos: identificar o perfil dos adolescentes escolares, trabalhadores quanto a sexo, idade, escolaridade, vínculo empregatício e ocorrência de acidentes ocupacionais; e determinar os tipos de acidentes, de lesões e partes do corpo acometidas.

\section{METODOLOGIA}

Trata-se de uma investigação descritiva, utilizando-se o modelo transversal de investigação, com abordagem e análise quantitativa de dados. Foi realizada na Escola Estadual João XXIII, no município de Ipatinga, Minas Gerais, no período de abril a agosto de 2008.

A instituição de ensino foi selecionada por pertencer à área de abrangência do Centro Regional de Referência em Saúde do Trabalhador (CEREST) de Ipatinga e, portanto, fazer parte da população considerada prioritária pelo plano de ação e metas de 2007/2008 desse setor, além de abrigar um enorme número de adolescentes que vivenciam a situação de trabalho em sua diversidade e singularidade, importantes para o que se propôs nesse estudo.

A população desse estudo foi de 2.500 adolescentes, sendo que 308 fizeram parte da amostra. A amostra foi probabilística e estratificada, e os adolescentes foram selecionados aleatoriamente, por meio de sorteio. Para o desenho amostral foi considerado um índice de erro de $5 \%$, um grau de confiança de $95 \%$ e uma proporção de $50 \%$, sendo considerado o tamanho da amostra de 334 adolescentes. Houve uma perda de 7,8\% (26) dos selecionados que foram excluídos da amostra por não cumprirem o critério de inclusão.

Como critérios de inclusão na amostra foram considerados os estudantes entre 14 e 18 anos de idade, trabalhadores e não trabalhadores, regularmente matriculados, que, voluntariamente, concordaram em participar do estudo e se encontravam presentes no momento da coleta. Os adolescentes que já haviam completado 18 anos assinaram o Termo de Consentimento Livre e Esclarecido (TCLE), e os menores de idade tiveram o consentimento do pai ou responsável.
Utilizou-se para a composição do grupo de adolescentes trabalhadores o conceito de trabalho referido nos estudos realizados em São Paulo "[...] toda atividade sistemática em que há uma obrigatoriedade de desenvolver tarefas, em horários e períodos predeterminados, seja no ambiente doméstico, seja para terceiros, com ou sem remuneração, tendo ou não vínculo empregatício formalizado" 4:975. 0 grupo que não trabalhava foi constituído pelos adolescentes que afirmaram não trabalhar, apenas estudar, no momento da coleta de dados.

Os acidentes de trabalho foram considerados como:

[...] evento súbito ocorrido no exercício de atividade laboral, independentemente da situação empregatícia e previdenciária do trabalhador acidentado, e que acarreta dano à saúde, potencial ou imediato, provocando lesão corporal ou perturbação funcional que causa direta ou indiretamente (concausa) a morte, ou a perda ou redução permanente ou temporária, da capacidade para o trabalho $0^{10: 11}$.

Como instrumento de coleta de dados foi utilizado um questionário autoaplicado, construído para uma pesquisa ampla sobre "Trabalho e violência em adolescentes estudantes: uma contribuição do Enfermeiro". Este instrumento foi testado em um estudo piloto e avaliado por três especialistas sobre o tema.

Foram selecionadas como variáveis para compor o estudo aquelas relacionadas às características demográficas (sexo, idade) e sociais (escolaridade, ocupação, renda) e às características dos acidentes (tipo de acidente, afastamento do trabalho, vínculo empregatício, tipo de agravo e parte do corpo atingida).

Após a coleta os dados sofreram categorização, codificação, registro e análise em um banco de dados por meio dos programas SPSS 13.0 e Excel versão 2003. As análises foram feitas a partir de estatísticas descritivas e apresentadas em gráficos e tabelas. 0 teste quiquadrado de Pearson foi utilizado para testar a significância da associação entre as variáveis de maior relevância para o estudo, sendo adotado o nível de 5\% para significância estatística.

0 estudo foi submetido aos procedimentos normativos do Comitê de Ética do Hospital Universitário Pedro Ernesto, na Universidade Estadual do Rio de Janeiro, sendo aprovado em 17 de março de 2008 sob o protocolo 2002-CEP/HUPE.

\section{RESULTADOS E DISCUSSÃO}

Os acidentes de trabalho compõem um grave problema de saúde pública em todo mundo, pois acometem grande número de trabalhadores, entre eles pessoas jovens em idade produtiva. São também potencialmente incapacitantes, acarretando consequências sociais e econômicas à vítima e onerando 0 sistema de saúde. ${ }^{10} \mathrm{Na}$ Bahia, em 2000, dos 31.096 benefícios concedidos devido a doenças ou agravos à saúde, 2.857 (7,5\%) 
eram por acidentes ocupacionais e seus custos foram estimados em $\mathrm{R} \$ 8,5$ milhões. ${ }^{11}$

Dos 334 estudantes selecionados, 308 adolescentes fizeram parte da amostra, tendo as idades entre 14 e 18 anos, com mediana de 17, moda de 17 e desvio-padrão de 1,2. Desses, 288 (93,5\%) estavam cursando o ensino médio, e 20 (6,5\%), a 8 a série do ensino fundamental, 177 (57,5\%) eram do sexo feminino, $131(42,5 \%)$ do sexo masculino, 168 $(54,5 \%)$ afirmaram ser trabalhadores e $140(45,5 \%)$, não trabalhadores.
Para o estudo dos acidentes ocupacionais foram considerados os 168 adolescentes trabalhadores; 70 (42\%) alegaram ter sofrido acidentes ocupacionais, sendo que a maioria estava com idades entre 16 e 17 anos. Os acidentes ocupacionais são eventos frequentes entre os jovens, fato esse comprovado por estudos realizados no Brasil e em outros países. ${ }^{4,8,12}$

Na Tabela 1, os resultados mostram que os trabalhadores do sexo masculino foram as maiores vítimas dos acidentes típicos, representando $54,9 \%$ ( $N=82$ ), e os do sexo feminino tiveram um percentual menor, com 29,1\% $(\mathrm{N}=86)$, diferença estatisticamente significante $(p=0,003)$.

Tabela 1 - Classificação dos acidentes ocupacionais e afastamentos ocorridos com estudantes trabalhadores, segundo sexo. Ipatinga, MG, 2008.

\begin{tabular}{|c|c|c|c|c|c|c|}
\hline \multirow{3}{*}{ VARIÁVEIS } & \multicolumn{4}{|c|}{ SEXO } & \multicolumn{2}{|c|}{ TOTAL } \\
\hline & \multicolumn{2}{|c|}{ Masculino } & \multicolumn{2}{|c|}{ Feminino } & \multirow{3}{*}{$\mathrm{N}$} & \multirow{3}{*}{$\%$} \\
\hline & $\mathrm{N}$ & $\%$ & $\mathrm{~N}$ & $\%$ & & \\
\hline \multicolumn{5}{|c|}{ Acidente Típico* } & & \\
\hline Sim & 45 & 54,9 & 25 & 29,1 & 70 & 42,0 \\
\hline Não & 35 & 42,7 & 59 & 68,6 & 94 & 56,0 \\
\hline Em branco & 2 & 2,4 & 2 & 2,3 & 4 & 2,0 \\
\hline Subtotal & 82 & 100,0 & 86 & 100,0 & 168 & 100,0 \\
\hline \multicolumn{7}{|c|}{ Acidente de trajeto** } \\
\hline Sim & 19 & 23,2 & 12 & 14,0 & 31 & 18,5 \\
\hline Não & 59 & 72,0 & 70 & 81,4 & 129 & 76,8 \\
\hline Em branco & 4 & 4,8 & 4 & 4,6 & 8 & 4,7 \\
\hline Subtotal & 82 & 100,0 & 86 & 100,0 & 168 & 100,0 \\
\hline \multicolumn{7}{|c|}{$\begin{array}{l}\text { Houve afastamento do } \\
\text { trabalho** }\end{array}$} \\
\hline Sim & 14 & 17,1 & 11 & 12,8 & 25 & 14,9 \\
\hline Não & 63 & 76,8 & 71 & 82,6 & 134 & 79,8 \\
\hline Em branco & 5 & 6,1 & 4 & 4,6 & 9 & 5,3 \\
\hline Subtotal & 82 & 100,0 & 86 & 100,0 & 168 & 100,0 \\
\hline
\end{tabular}

${ }^{*} p<0,05 \quad * *$ não houve diferença estatisticamente significante.

Os resultados da Tabela 1 remetem aos encontrados no estudo sobre os efeitos do aumento da idade mínima legal no trabalho de adolescentes no Brasil em $2005^{14}$. O fato de existir no país um número maior de adolescentes do sexo masculino inseridos no mercado de trabalho em comparação com os do sexo feminino justifica, segundo os autores ${ }^{14}$, uma maior suscetibilidade e, consequentemente, uma maior taxa de incidência de acidentes ocupacionais entre esses jovens. Além disso, alguns estudiosos ${ }^{6,15}$ afirmam que os adolescentes do sexo masculino assumem comportamentos de maior risco para acidentes (destemor diante do perigo, noções de invulnerabilidade, cultura de valentia e arrojamento) e vivenciam um processo de socialização diferentemente das jovens do sexo feminino, o que os torna mais predispostos a esse tipo de injúria..

A diferença de gênero supracitada foi percebida em estudos nacionais e internacionais. ${ }^{4,6,12}$ Porém, a maioria desses estudos utiliza dados de fonte secundária, como as bases de dados dos serviços de saúde ou do sistema previdenciário, que privilegia ou limita-se aos acidentes ocorridos com empregados formais ou com trabalhadores das indústrias, locais onde se concentra um maior número de pessoas do sexo masculino. Tal constatação 
justifica as altas taxas de incidência de acidentes entre os homens ocupados em comparação com as mulheres trabalhadoras. ${ }^{12}$

Também em relação aos dados da Tabela 1 , nota-se que $18,5 \%$ dos adolescentes já haviam se machucado, sido atropelados ou assaltados, indo ou voltando do trabalho. Este evento constitui os acidentes de trajeto que, segundo a legislação brasileira, são os acidentes ocorridos com 0 trabalhador no seu percurso de casa para o trabalho, e viceversa.

A ocorrência de acidentes de trajeto entre o grupo estudado pode ser justificada por uma estreita e progressiva ligação da exposição dos adolescentes ocupados aos fenômenos urbanos e uma extrapolação desses eventos para o ambiente externo da empresa (espaço da rua), tornando-se significativa a interação da violência urbana com o deslocamento dos trabalhadores. ${ }^{9}$

Os acidentes de transporte foi o tipo de injúria mais frequente entre pessoas de 0 a 19 anos, residentes em Ipatinga nos anos de 1999 a 2000, de acordo com um estudo realizado no município. $^{15}$

Vale ressaltar que, neste estudo, os autore ${ }^{15}$ não verificaram se havia relação entre as injúrias sofridas pelos jovens e seu status de ocupação. Porém, foi importante por apontar a bicicleta como principal veículo utilizado pelas vítimas no momento do acidente. 0 não uso dos equipamentos de segurança por $100 \%$ dos acidentados foi considerado o fator de risco mais importante para a ocorrência desses eventos.

A utilização da bicicleta por trabalhadores e pela população em geral como meio de transporte é comum e cultural em
Ipatinga. Além disso, a Escola João XXIII localiza-se próximo à Rodovia BR 381 e à Avenida Brasil, vias com grande fluxo de veículos, o que pode aumentar o risco de acidentes de trajeto entre os jovens desse estudo.

Em 2008 (dados computados de janeiro a novembro), o Serviço de Atendimento Móvel de Urgência de Ipatinga registrou 2.100 atendimentos, sendo $56 \%$ devidos a acidentes de trânsito; $85 \%$ de um total de 1.200 acidentes envolveram veículo sobre duas rodas e ocorreram 34 mortes. Dessas, 14 envolviam bicicletas como meio de transporte. ${ }^{16}$

Os dados da Tabela 1 indicam que, dos adolescentes estudados, 14,9\% alegaram terem sido afastados das atividades laborais devido aos acidentes de trabalho e nos remetem aos estudos realizados em Salvador (Bahia). Segundo os autores ${ }^{11}$, foram estimados, aproximadamente, meio milhão de dias perdidos de trabalho no ano de 2000 devido aos acidentes ocupacionais nesse município. Portanto, esses eventos são os principais motivos relacionados às perdas de dias trabalhados, acarretando impactos negativos na produtividade do país e sofrimento aos vitimizados e seus familiares.

Considerando a situação empregatícia entre os trabalhadores acidentados, os resultados da Tabela 2 evidenciam que a maioria, 51,4\%, não tinha carteira assinada, $34,3 \%$ a possuía e $7,1 \%$ se encontrava em período de experiência na empresa. Houve diferença estatisticamente significante quando foram comparadas as variáveis "acidentes" e "vínculo empregatício" ( $p<0,000)$.

Tabela 2 - Situação empregatícia em relação à ocorrência de acidentes ocupacionais com estudantes trabalhadores. Ipatinga, MG, 2008.

JÁ SE ACIDENTOU

\begin{tabular}{|c|c|c|c|c|c|c|c|c|}
\hline \multirow{2}{*}{$\begin{array}{c}\text { VÍNCULO } \\
\text { EMPREGATÍCIO }\end{array}$} & \multicolumn{2}{|c|}{ Sim } & \multicolumn{2}{|c|}{ Não } & \multicolumn{2}{|c|}{ Em branco } & \multicolumn{2}{|c|}{ Total } \\
\hline & N & $\%$ & $N$ & $\%$ & $\mathrm{~N}$ & $\%$ & $N$ & $\%$ \\
\hline Carteira assinada & & & & & & & & \\
\hline Sim & 24 & 34,3 & 44 & 46,8 & 1 & 25,0 & 69 & 41,1 \\
\hline Não & 36 & 51,4 & 33 & 35,1 & 0 & 0,0 & 69 & 41,1 \\
\hline Período de experiência & 5 & 7,1 & 13 & 13,8 & 0 & 0,0 & 18 & 10,7 \\
\hline Em branco & 5 & 7,1 & 4 & 4,3 & 3 & 75,0 & 12 & 7,1 \\
\hline Total & 70 & 100,0 & 94 & 100,0 & 4 & 100,0 & 168 & 100,0 \\
\hline
\end{tabular}

${ }^{*} P<0,000$

Os dados encontrados diferem do estudo de base populacional realizado em Salvador, onde os autores ${ }^{12}$ não verificaram diferença estatisticamente significativa entre trabalhadores acidentados com carteira e sem carteira assinada. Para esses autores, ${ }^{12}$ as diferenças de gênero e vínculo de trabalho (formal e informal) não são os fatores mais importantes para definir os padrões de risco em geral para a ocorrência de acidentes, mas, sim, se deve explorar com maior especificidade as ocupações, as atividades desempenhadas pelo trabalhador, avaliar as condições dos ambientes de trabalho e promover fiscalização efetiva da adoção de normas de higiene e segurança do trabalho.

Devido às diferenças de atividades ocupacionais entre 0 grupo estudado no que tange ao sexo, houve, também, 
distinções relativas aos tipos de acidentes sofridos pelos jovens trabalhadores, que podem ser vistas na Tabela 3. Enquanto $33,8 \%$ dos indivíduos do sexo masculino afirmaram ter sofrido "cortes e perfurações", $25 \%$ das jovens referiram ter sido vítimas de "queda", seguida de "contato com substância quente" (17,5\%) e "choque elétrico" (17,5\%).

Tabela 3 - Características dos acidentes de trabalho entre adolescentes trabalhadores, segundo sexo. Ipatinga, MG, 2008.

\begin{tabular}{|c|c|c|c|c|c|c|}
\hline \multirow{3}{*}{ TIPO DE ACIDENTE } & \multicolumn{4}{|c|}{ SEXO } & \multicolumn{2}{|c|}{ TOTAL } \\
\hline & \multicolumn{2}{|c|}{ Masculino } & \multicolumn{2}{|c|}{ Feminino } & \multirow[b]{2}{*}{$\mathrm{N}$} & \multirow[b]{2}{*}{$\%$} \\
\hline & $N$ & $\%$ & $\mathrm{~N}$ & $\%$ & & \\
\hline Queda & 10 & 12,5 & 10 & 25,0 & 20 & 16,7 \\
\hline $\begin{array}{l}\text { Ating ido por objeto em } \\
\text { movimento }\end{array}$ & 8 & 10,0 & 3 & 7,5 & 11 & 9,2 \\
\hline Cortes e perfurações & 27 & 33,8 & 6 & 15,0 & 33 & 27,5 \\
\hline Contato com substância quente & 10 & 12,5 & 7 & 17,5 & 17 & 14,2 \\
\hline $\begin{array}{l}\text { Contato com superfície muito } \\
\text { quente ou muito fria }\end{array}$ & 5 & 6,2 & 3 & 7,5 & 8 & 6,7 \\
\hline Choque elétrico & 8 & 10,0 & 7 & 17,5 & 15 & 12,5 \\
\hline Manuseio de máquinas & 6 & 7,5 & 0 & 0,0 & 6 & 5,0 \\
\hline $\begin{array}{l}\text { Contamina ção por material } \\
\text { biológico }\end{array}$ & 0 & 0,0 & 1 & 2,5 & 1 & 0,8 \\
\hline Ina lação de gases & 1 & 1,2 & 0 & 0,0 & 1 & 0,8 \\
\hline Contato com substância química & 3 & 3,8 & 2 & 5,0 & 5 & 4,2 \\
\hline Outros & 2 & 2,5 & 1 & 2,5 & 3 & 2,5 \\
\hline TOTAL & 80 & 100,0 & 40 & 100,0 & 120 & 100,0 \\
\hline
\end{tabular}

Quanto ao tipo de agravos, a maior parte dos homens e mulheres foi vítima de "queimadura" $(26,9 \%)$ e "cortes superficiais" (22,4\%), não havendo diferenças estatisticamente significativas entre os dois grupos.

Os acidentes de trabalho estão relacionados à não utilização de Equipamentos de Proteção Individual (EPI), como botas, capacete, óculos de proteção, cinto de segurança e luvas, bem como à falta de informações sobre riscos espećíicos e modos efetivos de sua prevenção, tanto por parte do patrão como do trabalhador. 12,17

Em um estudo realizado na Bahia, os autore ${ }^{12}$ observaram evidências de que há uma tendência de responsabilização do próprio trabalhador pelo seu acidente, o que mantém a invisibilidade das condições inseguras nos locais de trabalho. Essa situação denota a importância de uma cultura de prevenção de riscos, que deve ser enfatizada na empresa a partir de um trabalho educativo, voltado para a cultura de mudança de atitude e de estilo de vida, com enfoque na preservação da saúde.
Na Tabela 3 observa-se que as partes do corpo mais atingidas nos acidente foram mãos e dedos, apontados por $40,4 \%$ dos adolescentes, seguidas dos membros inferiores (região coxofemoral, coxa, joelho e perna), citados por 20,6\%, e superiores (braço, antebraço e cotovelo), por 19,1\%. Essas ocorrências podem ser justificadas pela crescente informalidade dos vínculos trabalhistas (que dificulta a fiscalização dos ambientes laborais), precariedade das condições de trabalho, falta de destreza e experiência no manuseio de máquinas, objetos e ferramentas perigosas (devido à imaturidade psicomotora e cognitiva do adolescente e à inadequação dos equipamentos e ferramentas às suas características corporais), sobrecarga (devido à exposição dos jovens a esforços superiores a sua capacidade física), não uso dos EPI, pela falta de informação e treinamento sobre os riscos específicos e modos efetivos de prevenção, tanto por parte do patrão como do trabalhador. ${ }^{12,17}$

Diante dos achados, torna-se fundamental ter 0 conhecimento de que os adolescentes se encontram em período 
de crescimento e desenvolvimento ${ }^{18}$, com capacidade e adolescente, geralmente, estão inseridos em locais insalubres limitações para o labor diferentes das dos adultos. Além disso, deve-se considerar que, em situações ilegais de trabalho, 0 e menos sujeitos à fiscalização e cobranças das medidas de proteção, o que thes confere uma maior vulnerabilidade aos agravos à saúde., 4

Tabela 4 - Características dos acidentes de trabalho entre adolescentes trabalhadores, segundo sexo. Ipatinga, MG, 2008 (Conclusão).

\begin{tabular}{|c|c|c|c|c|c|c|}
\hline \multirow{3}{*}{ TIPO DE AGRAVOS } & \multicolumn{4}{|c|}{ SEXO } & & \\
\hline & \multicolumn{2}{|c|}{ Masculino } & \multicolumn{2}{|c|}{ Feminino } & \multicolumn{2}{|c|}{ TOTAL } \\
\hline & $N$ & $\%$ & $N$ & $\%$ & N & $\%$ \\
\hline Cortes superficia is & 22 & 26,5 & 8 & 15,7 & 30 & 22,4 \\
\hline Escoriações & 15 & 18,1 & 8 & 15,7 & 23 & 17,1 \\
\hline Queimaduras & 22 & 26,5 & 14 & 27,4 & 36 & 26,9 \\
\hline Perfuração & 6 & 7,2 & 2 & 4,0 & 8 & 5,9 \\
\hline Estiramento/ Entorse /Luxação & 2 & 2,4 & 2 & 4,0 & 4 & 3,0 \\
\hline Fraturas & 2 & 2,4 & 0 & 0,0 & 2 & 1,5 \\
\hline Hematoma / Hemorragia & 5 & 6,0 & 7 & 13,7 & 12 & 9,0 \\
\hline Choque elétrico & 7 & 8,4 & 5 & 9,8 & 12 & 9,0 \\
\hline Contusão na cabeça & 1 & 1,2 & 4 & 7,8 & 5 & 3,7 \\
\hline Outros & 1 & 1,2 & 1 & 1,9 & 2 & 1,5 \\
\hline Subtotal & 83 & 100,0 & 51 & 100,0 & 134 & 100,0 \\
\hline \multicolumn{7}{|l|}{ Parte do corpo atingida } \\
\hline Braço / Antebraço / Cotovelo & 18 & 22,8 & 8 & 14,0 & 26 & 19,1 \\
\hline Mão / Dedos & 31 & 39,2 & 24 & 42,1 & 55 & 40,4 \\
\hline $\begin{array}{l}\text { Coxofemural / Coxa / Joelho / } \\
\text { Perna }\end{array}$ & 15 & 19,0 & 13 & 22,8 & 28 & 20,6 \\
\hline Dorso do pé / Planta do pé & 7 & 8,9 & 6 & 10,5 & 13 & 9,6 \\
\hline Pescoço & 0 & 0,0 & 1 & 1,8 & 1 & 0,7 \\
\hline Coluna & 3 & 3,8 & 5 & 8,8 & 8 & 6,0 \\
\hline Ombro & 1 & 1,3 & 0 & 0,0 & 1 & 0,7 \\
\hline Em branco & 4 & 5,0 & 0 & 0,0 & 4 & 2,9 \\
\hline Subtotal & 79 & 100,0 & 57 & 100,0 & 136 & 100,0 \\
\hline
\end{tabular}

* Não houve diferença estatisticamente significante entre os dois sexos.

** Os valores referem-se a todos os resultados obtidos com a pergunta, uma vez que se admitia mais de uma resposta. 


\section{CONCLUSÃO}

A realização deste estudo e os resultados encontrados revelaram a realidade do trabalho precoce dos adolescentes estudantes da Escola Estadual João XXIII, mostrando a grande relevância e magnitude dos acidentes ocupacionais para esses jovens trabalhadores. Teve como limitação o não aprofundamento sobre a percepção do que esses eventos representam para a vida desses estudantes, sendo sugestiva a realização de estudos longitudinais com avaliação quantitativa e qualitativa dos dados no intuito de fortalecer as ações do CEREST na promoção da atenção integral ao adolescente trabalhador.

Entre os adolescentes trabalhadores, $42 \%$ alegam ter sido vítimas de acidentes no ambiente laboral e 14,9\% tiveram que se afastar do trabalho por esse motivo. Entre os jovens acidentados, 51,4\% não tinham carteira assinada, os cortes e perfurações foram os acidentes que mais ocorreram (27,5\%), as queimaduras constituíram os principais agravos sofridos (26,9\%) e as partes do corpo mais afetadas foram as mãos e os dedos (40,4\%). Os jovens do sexo masculino foram mais acometidos que os do sexo feminino e a faixa etária da maioria dos vitimizados se encontrava entre 16 e 17 anos de idade. Houve um número expressivo de acidentes de trajeto (18,5\%), apontando uma estreita relação do processo produtivo com a violência urbana.

Os acidentes decorrentes de situações de trabalho configuram-se como uma expressão da violência social contra os jovens e uma questão que deve ser tratada com prioridade na agenda dos serviços de saúde pública. 0 CEREST/Ipatinga tem um papel relevante na criação e implementação de ações estratégicas para sua redução e prevenção, devendo, ainda, promover ações de vigilância dos ambientes laborais e traçar medidas para melhoria das condições de trabalho dos adolescentes da sua área de abrangência. Vale ressaltar que suas ações devem demandar uma articulação com outros setores fora da saúde, entre eles as Secretarias Municipais de Educação, Ação Social, Serviços Urbanos e de Meio Ambiente, Conselhos de Direito da Criança e do Adolescente, Ministério Público, Ministério do Trabalho e outros.

Dentre as ações de promoção e vigilância à saúde do trabalhador adolescente, o enfermeiro, junto à equipe de saúde, deve promover uma educação transformadora que focalize o valor da vida e cultura de mudança de estilo de vida, estimulando o autocuidado. Para que as ações educativas sejam efetivas, torna-se necessário traçar como objetivos: a) abordar a importância do uso de EPI; b) manter a organização, iluminação, ventilação e saneamento adequados nos locais de trabalho; c) prevenir e/ou controlar acidentes e doenças laborais; d) prestar cuidados no tratamento e na reabilitação dos trabalhadores que sofrem ou já sofreram acidentes ocupacionais; e) aplicar a Portaria № 777/04 (notificar e investigar, obrigatoriamente, todos os acidentes que acometem adolescentes menores de 18 anos). A investigação dos casos deve ser realizada em conjunto com os órgãos públicos do Ministério do Trabalho, Polícias Civil e Militar e Ministério Público.

Deste modo, o enfermeiro e a equipe de saúde estarão contribuindo para efetivação do bem-estar social, garantindo uma atenção integral aos adolescentes, buscando reduzir o seu ingresso precoce no trabalho, conforme previsto na Política Nacional de Erradicação do Trabalho Infantil e Proteção do Trabalhador adolescente.

\section{REFERÊNCIAS}

1. Lei Federal: 8069, de 13 de julho de 1990. Dispõe sobre o Estatuto da Criança e do Adolescente e dá outras providências.

2. Ramos FRS. Bases para uma re-significação do trabalho de enfermagem junto ao adolescente. In: Ramos FRS, Monticelli M, Nitschke RG, organizadores. Projeto Acolher. Adolescer: compreender, atuar, acolher. Brasília (DF): ABEn; 2001. p.11-18.

3. Saito MI. Adolescência, cultura, vulnerabilidade e riscos: a prevenção em questão. In: Saito MI, Silva LEV. Adolescência: prevenção e risco. São Paulo (SP): Atheneu; 2001. p.33-38.

4. Fischer FM, Oliveira DC, Teixeira LR, Teixeira MCTV, Amaral MA. Efeitos do trabalho sobre a saúde de adolescentes. Cienc Saude Colet 2003; 8(4): 973-84.

5. Asmus CIRF, Raymundo CM, Barker SL, Pepe CCCA, Ruzany MH. Atenção integral à saúde de adolescentes em situação de trabalho: lições aprendidas. Cienc Saude Colet 2005 out/dez; 10 (4): 953-60.

6. Ministério da Saúde (BR). Trabalho Infantil: diretrizes para atenção integral à saúde de criança e adolescentes economicamente ativos. Brasília (DF); 2005.

7. Rocha EG, Freitas VP. A proteção legal do jovem trabalhador. Revista da UFG [on-line] 2004 jun; [citado 18 maio 2008]; 6(1): [aprox. 5 telas]. Disponível em http://www.proec.ufg.br/revista_ufg/juventude/ legal.html.

8. Instituto Brasileiro de Geografia e Estatística- IBGE. Crianças, adolescentes e jovens: indicadores sociais. Rio de Janeiro (RJ); 2007.

9. Minayo CG, Meirelles ZV. Crianças e adolescentes trabalhadores: um compromisso para a saúde coletiva. Cad Saude Publica [on-line] 1997; [citado 30 mar 2008]; 13(supl 2): [aprox. 6 telas]. Disponível em http://www.scielo.br/pdf/csp/v13s2/1370.pdf

10. Ministério da Saúde (BR). Notificação de acidentes de trabalho fatais, graves e com crianças e adolescentes, 2. Brasilia (DF); 2006.

11. Santana VS, Araujo Filho JB, Oliveira PRA, Branco AB. Acidentes de trabalho: custos previdenciários e dias de trabalho perdidos. Rev Saude Publica 2006; 40(6): 1004-12.

12. Santana V, Maia AP, Carvalho C, Luz G. Acidentes de trabalho não fatais: diferenças de gênero e tipo e contrato de trabalho. Cad Saude Publica $2003 \mathrm{mar} / \mathrm{abr}$; 19(2): 481-93. 
Trabalho precoce e acidentes ocupacionais

13. Santana VS, Itaparica M, Amorim AM, Araújo Filho JB, Araújo G, Oliveira $M$ et al. Acidentes de trabalho não fatais em adolescentes. Cad Saude Publica 2003 mar/abr; 19(2):407-20.

14. Ferro AR, Kassouf AL. Efeitos do aumento da idade mínima legal no trabalho dos brasileiros de 14 e 15 anos. Rev Econ Sociol 2005 out; 43(2):307-29.

15. Gaspar VLV, Lamounier JA, Cunha FM, Gaspar JC. Fatores relacionados a hospitalizações por injúrias em crianças e adolescentes. J Pediatr 2004 dez; 80(6): 447-52.
16. Perigo viaja sobre duas rodas: mortes no trânsito em Ipatinga superam média mundial-adverte SAMU. Diário do Aço, Ipatinga 2008 dez ;23(8): 998-94.

17. Oliveira BRG, Robazzi MLCC. 0 trabalho na vida dos adolescentes: alguns fatores determinantes para o trabalho precoce. Rev LatinoAm. Enfermagem 2001 maio; 9(3): 83-9.

18. Spindola T, Silva LFF. Perfil epidemiológico de adolescentes atendidas no pré-natal de um hospital universitário. Esc Anna Nery Rev Enferm 2009 jan/mar; 13(1): 99-107. 